\title{
OSTEORRADIONECROSE: PREVENÇÃO E TRATAMENTO ODONTOLÓGICO
}

Ana Luiza ROCHA, Carla da Cruz ROMA, Juliana Garcia Camilo MIRANDA, Hélio de Jesus KIYOCHI JÚNIOR, Mariliani Chicarelli da SILVA

A osteorradionecrose (ORN) dos maxilares é uma das mais temidas complicações bucais tardias da radioterapia contra neoplasias da cabeça e pescoço. Trata-se de uma necrose isquêmica induzida pela radiação, onde há evidências imaginológica e clínica de necrose óssea. $O$ tratamento preventivo freqüentemente diminui os efeitos provocados pela radioterapia. O número de indivíduos que apresentam neoplasias malignas na cavidade bucal é ainda hoje significativo, e ao terem suas lesões diagnosticadas, já as apresentam num estágio onde não é mais possível apenas o tratamento cirúrgico, tendo assim como alternativa a radioterapia ou a associação dos dois procedimentos. A radioterapia pode ter três finalidades: curativa (extermina as células neoplásicas), remissiva (reduz parte do tumor) ou sintomática (tratamento da dor localizada). São observadas na cavidade bucal, durante e logo após a radioterapia, alterações como mucosite, diminuição do fluxo salivar, alterações no paladar, infecções oportunistas, cárie de radiação, mucosite crônica, periodontopatia e osteorradionecrose. Através de uma revisão de literatura este trabalho visa caracterizar as alterações que podem ocorrer em pacientes submetidos à radioterapia no que diz respeito à osteorradionecrose, enfatizando a importância da participação e conhecimento do assunto pelo cirurgiãodentista para a resolução do problema e promoção de qualidade de vida aos seus pacientes. 